Discussion Paper No. 853

\title{
REGULATED INPUT PRICE, VERTICAL SEPARATION, AND LEADERSHIP IN FREE ENTRY MARKETS
}

Toshihiro Matsumura

Noriaki Matsushima

August 2012

The Institute of Social and Economic Research Osaka University

6-1 Mihogaoka, Ibaraki, Osaka 567-0047, Japan 


\title{
Regulated input price, vertical separation, and leadership in free entry markets*
}

\author{
Toshihiro Matsumura ${ }^{\dagger}$ \\ Institute of Social Science, The University of Tokyo \\ Noriaki Matsushima $a^{\ddagger}$ \\ Institute of Social and Economic Research, Osaka University
}

August 9, 2012

JEL classification numbers: L51, L13

Key words: network industry, access charge, manipulation of accounting, regulation

${ }^{*}$ The authors gratefully acknowledge financial support from a Grant-in-Aid for Basic Research from the Japanese Ministry of Education, Science and Culture. Needless to say, we are responsible for any remaining errors.

${ }^{\dagger}$ Toshihiro Matsumura, Institute of Social Science, The University of Tokyo, Hongo 7-3-1, Bunkyo, Tokyo 113-0033, Japan. E-mail: matsumur@iss.u-tokyo.ac.jp

${ }^{\ddagger}$ Corresponding author: Noriaki Matsushima, Institute of Social and Economic Research, Osaka University, Mihogaoka 6-1, Ibaraki, Osaka 567-0047, Japan. Phone: +81-6-6879-8571. E-mail: nmatsush@iser.osakau.ac.jp 


\begin{abstract}
We examine incentives of bottleneck facility holders to manipulate access charge accounting in free entry downstream markets. We consider the situation wherein one firm holds an upstream bottleneck facility and new entrants use it at the regulated price (access fee) to provide final products. The bottleneck facility holder affects the regulated input price. We investigate how vertical separation affects the incentive for manipulation and the resulting input price. We find that the results depend on whether the incumbent is the Stackelberg leader in the product market. If the incumbent cannot take leadership in the product market and faces Cournot competition, vertical separation reduces the incentive for manipulation and the resulting input price. The opposite result is derived when the incumbent can take leadership in the product market.
\end{abstract}




\section{Introduction}

Competition between a firm holding essential facilities (usually a dominant firm) and firms not holding them has been widely observed in many industries such as overnight delivery, telecommunications, electric power, and natural gas distribution. In particular, dominant firms in Japan are not vertically separated in the telecommunications, electric power, and gas distribution industries. Dominant firms were previously legal monopolists, and they have competed against new entrants since the liberalization of these markets. In these network industries, new entrants pay an access fee to the dominant firms. This access fee affects the new entrants' marginal costs and thus significantly affects the performance of the markets.

The access fee is typically regulated by the government. Considerable literature on the desirable and/or existing rules for levying the access charge, such as the efficient component pricing rule (ECPR), the total element long-run incremental cost (TELRIC), and a historical cost approach, exists $;^{1}$ moreover, charges based on the costs of essential facilities are currently levied all over the world. For example, in Japan, TELRIC has been adopted by traditional local telecommunications, while the historical cost approach has been adopted in the optical fiber networks, electric power, and natural gas distribution industries. In the EU, although the rules are different for different countries, cost-based approaches have been adopted in most industries and in most countries.

In practice, however, firms often influence the regulated input price (access charge) by manipulating the accounting costs, whereas in principle, the rule for calculating the access charge is determined by a neutral government and there is no room for manipulation. ${ }^{2}$ For instance, using a dataset on state campaign contributions by telecommunications companies in

\footnotetext{
${ }^{1}$ For a general description of the access charge, see Vogelsang (2003) and Rey and Tirole (2007). See also Laffont and Tirole (1994), Economides and White (1995), Hausman (1997), Armstrong and Vickers (1998), Ida (2001), Sappington (2006), and Higgins and Mukherjee (2010). Further, see Hori and Mizuno (2006), Mizuno and Shinkai (2006), Ida and Anbashi (2008), and Gautier and Mitra (2008) for the dynamic efficiency of access charge rules.

${ }^{2}$ For discussions on these activities in the general context of regulation policies, see Viscusi et al. (2005).
} 
the United States, de Figueiredo and Edwards (2007) find that there is a correlation between the relative levels of contributions by firms and the level of local loop prices (regulated access prices). In Japan, integrated gas companies insisted that the costs of vaporizers and pumps of liquidated natural gas (LNG) tanks should be included in the access charge accounting for gas distribution pipeline networks. They made substantial efforts to rationalize their argument in front of the Gas Energy Committee of the Advisory Committee for Natural Resource and Energy, the agency that determines the rules for access charge accounting. These companies succeeded in persuading the committee to adopt a resolution to include these costs in the access charge and maintained that resolution for more than 15 years. Similar instances have been widely observed in the telecommunications and electric power distribution industries in Japan. In this paper, we consider a situation wherein the access charge is influenced by the firms holding the bottleneck facilities. ${ }^{3}$

Another important policy topic is whether dominant firms should be allowed to hold essential facilities. Vertical separation is always an important policy issue in this field, and legal and ownership unbundling has been widely observed, especially in the EU. It is often insisted that vertical separation is beneficial because it deters manipulation by vertically integrated firms.

In this paper, we discuss the means by which vertical separation affects the regulated input price. First, we formulate a model in which $n$ firms (firm 1, firm $2, \ldots$, firm $n$ ) compete in a final product market and one monopoly input supplier, firm 0 , holds an essential facility. The number of firms is endogenously determined (free entry market). Firm 1 is the incumbent firm (formerly legal monopolist). We compare two situations: firms 0 and 1 are vertically integrated (vertical integration case) and no firm is vertically integrated (vertical separation case). We also consider the two cases concerning the leadership of the incumbent firm, firm 1. One is the Stackelberg model in which firm 1 can commit to the output level before the entry

\footnotetext{
${ }^{3}$ Baron (2001) emphasizes the importance of those nonmarket strategies including lobbying, self-regulation, and corporate social responsibility.
} 
of new entrants (firm $2, \ldots$, firm $n$ ), and the other is Cournot model in which all downstream firms (firm 1 , firm $2, \ldots$, firm $n$ ) produce independently.

Whether the existing incumbent firm takes leadership in the downstream market is an important matter in deregulated industries. In some cases, the historically incumbent firms have dominant positions (Weisman (1995), Sarmento and Brandão (2007)), implying that those incumbent firms take leadership in the downstream markets; thus, considering Stackelberg competition is reasonable for researchers. In other cases, such incumbent firms do not have significant market shares (Beard et al. (2001)), implying that considering Cournot competition is reasonable for researchers. The difference between the market positions of historically incumbent firms crucially depends on how to deregulate those former regulated markets, entry conditions, technological properties, and so on. We therefore think that comparing the two competition modes (Cournot and Stackelberg) is important in the context of deregulated markets.

We find that the effect of vertical separation crucially depends on whether the incumbent firm takes leadership in the product market. If the incumbent cannot take leadership at the product market, vertical separation reduces the incentive for manipulation of accounting and thus reduces the resulting regulated input price. On the contrary, if the incumbent can take leadership at the product market, vertical separation increases the incentive for manipulation and thus raises the input price. Thus, to reduce the manipulation and to stimulate new entries by vertical separation, eliminating the leadership position by the incumbent is important.

We explain why Cournot and Stackelberg yield opposite policy implications for the vertical separation policy. First, consider the Cournot competition (where the incumbent, firm 1, cannot take leadership). Under vertical integration, an increase in the input price reduces other firms' outputs and thus increases firm 1's output. This production substitution increases the profit of firm 1, and thus firm 0 , the holder of bottleneck facility, has a stronger incentive to manipulate the input price because firm 0 maximizes the joint profits of firms 0 and 1 under vertical integration. This effect disappears under vertical separation. This is why 
vertical integration stimulates the manipulation by firm 0. Next, consider the Stackelberg competition (where the incumbent, firm 1, can take leadership). As discussed in Etro (2006), the incumbent produces aggressively, regardless of the input price. Thus, in contrast to the Cournot case, the strategic effect of raising the input price disappears under vertical integration. On the other hand, an increase in the input price reduces the output and the profit of firm 1, but firm 0 does not take this reduction into account under vertical separation. Thus, firm 0 has a stronger incentive to raise the input price. This is why vertical separation stimulates the manipulation under Stackelberg competition.

We review related papers. There are two research lines that are closely related to our paper. One is the literature on strategic commitment in free entry markets. Etro (2006, 2007) clearly shows that the incumbent leader engages in aggressive strategic behavior to restrict new entries in free entry markets in a general context. He derives many important policy implications in the context of competition policies. ${ }^{4}$ We introduce this strategic behavior in the context of vertical separation/integration policy and regulated input prices. The entry restrictions in markets with a bottleneck facility have been significantly weakened. We observe the new entry of private firms in these markets such as the electric power, natural gas distribution, and telecommunication markets in many European and Asian countries. Therefore, the analysis of free entry market in this context is quite important.

The other research line is the literature on raising rivals' costs. In the literature on vertically related industries, many works have already pointed out that vertically integrated firms have strong incentives to raise their rivals' costs. Economides (1998) investigates Cournot competition in a downstream market and shows that the vertically integrated firm has an incentive to exclude the rivals through a prohibitive access charge. Mandy and Sappington (2007) show that the vertically integrated firm has an incentive to engage in cost-increasing sabotage regardless of whether there is Cournot or Bertrand competition in the downstream

\footnotetext{
${ }^{4}$ The literature on strategic behavior in free entry markets and discussions of policy implications has become rich and diverse. See, among others, Brandão and Castro (2007), Davidson and Mukherjee (2007), Etro (2008, 2011), Ino and Matsumura (2010, 2012), Marjit and Mukherjee (2008), and Mukherjee and Mukherjee (2008).
} 
market, but has a weak (strong) incentive to engage in demand-reducing sabotage when there is Bertrand (Cournot) competition. The discussions on increasing the rivals' costs and costincreasing sabotage in this context are also provided by Beard et al. (2001) (see also the papers cited by them). Bustos and Galetovic (2009) discuss a case in which a bottleneck monopoly endogenously determines its vertical structure (integration or separation) and the degree of sabotage. Our paper differs in two crucial ways from these works. Under vertical separation, the upstream firm has no incentive to engage in sabotage activities because these activities never increase the revenue and thus the profits of the upstream firm. On the contrary, raising the regulated input price raises the profit of the upstream firm, and thus the upstream firm has an incentive to raise the input price even under vertical separation. Another and more important difference is that all works mentioned above assume that the number of firms is given exogenously, whereas we consider free entry markets.

The remainder of this paper is organized as follows. Section 2 formulates the model. Section 3 presents the result under Cournot competition. Section 4 presents the result under Stackelberg competition. Section 5 checks the robustness of the result in Section 4. Section 6 concludes the paper.

\section{The model without leadership}

In this section, we formulate a model wherein downstream firms face Cournot competition in the final product market. We consider two cases: (1) A vertically integrated firm holding a bottleneck facility exists (vertical integration); (2) The government undertakes vertical separation of the firm holding the bottleneck facility (vertical separation).

We consider an oligopoly model. Firm 0 holds a bottleneck facility. Firm 1 is the incumbent firm and firm $i(i=2, \ldots, n)$ is a new entrant. The number of new entrants is endogenously determined by the free entry condition discussed below. Firm $i(i=1, \ldots, n)$ uses the bottleneck facility held by firm 0 and pays $f y_{i}$ to firm 0 , where $f$ is the input price (per unit access fee of the bottleneck facility) and $y_{i}$ is firm $i$ 's output. We assume that the 
marginal production cost is constant, common among firms, and normalized to zero (except for the access fee).

In the first stage, the input price (access fee) $f$ is determined. Let $M(f)$ denote firm 0 's costs for manipulation of the access charge accounting. We implicitly assume that the input price is zero if firm 0 does not make any effort. That is, the input price is regulated but can be affected by firm 0's efforts.

In the second stage, given the input price, $f$, new entrants determine whether to enter the market.

In the third stage, firms engage in Cournot competition. Firm $i(i=1, \ldots, n)$ independently produces perfectly homogeneous products for which the market demand function is given by $p(Y)$, where $Y$ is the total output of the firms (price as a function of quantity). We assume that $p^{\prime}<0$. We also assume that $p^{\prime \prime} y_{i}+p^{\prime}<0$ for all $y_{i} \leq Y$ so as to ensure that the reaction curve at the Cournot competition stage is downward sloping (strategic substitute). The profits of firms 0 and $i$ are given as

$$
\pi_{0}=f \sum_{j=1}^{n} y_{j}-M(f), \quad \pi_{i}=(p(Y)-f) y_{i}-K(i=1, \ldots, n),
$$

where $K>0$ is the entry cost. We assume that $M^{\prime}(f) \geq 0$ and that $M^{\prime \prime}(f)>0$ in order

to ensure the concavity of firm 0's payoff function. We assume that $M^{\prime}(0)=0$ in order to ensure interior solutions in the first stage. We also assume that the number of new entrants is strictly positive under the Cournot competition.

\section{Equilibrium outcome without leadership by the incumbent}

\section{$3.1 \quad$ Vertical integration}

First, we consider the vertical integration case, that is, firms 0 and 1 are integrated vertically and maximize their joint profits.

Consider the third stage. From (1), the first-order conditions of the firms in the third 
stage are given by

$$
\begin{aligned}
p+p^{\prime} y_{1} & =0, \\
p+p^{\prime} y_{i}-f & =0,(i=2,3, \ldots, n) .
\end{aligned}
$$

In the second stage, the free entry condition (zero-profit condition) must hold for $i=2, \ldots, n$ :

$$
(p(Y)-f) y_{i}=K
$$

These three conditions in (2), (3), and (4) yield the equilibrium outcome given the regulated input price $f$. We investigate how a change in the input price affects the equilibrium outcome. The total differentials of these three conditions are given as

$$
\begin{array}{llll}
\left(p^{\prime \prime} y_{1}+2 p^{\prime}\right) d y_{1} & +(n-1)\left(p^{\prime \prime} y_{1}+p^{\prime}\right) d y_{i} & +y_{i}\left(p^{\prime \prime} y_{1}+p^{\prime}\right) d n & =0, \\
\left(p^{\prime \prime} y_{i}+p^{\prime}\right) d y_{1} & +\left((n-1) p^{\prime \prime} y_{i}+n p^{\prime}\right) d y_{i} & +y_{i}\left(p^{\prime \prime} y_{i}+p^{\prime}\right) d n & =d f, \\
p^{\prime} y_{i} d y_{1} & +(n-2) p^{\prime} y_{i} d y_{i} & +y_{i}^{2} p^{\prime} d n & =y_{i} d f,
\end{array}
$$

where we use $p-f=-p^{\prime} y_{i}$ in (3) to derive the last equation in (5). These equations in (5) yield

$$
\begin{aligned}
\frac{d y_{1}}{d f} & =-\frac{2\left(p^{\prime}+p^{\prime \prime} y_{1}\right)}{p^{\prime}\left(2 p^{\prime}+p^{\prime \prime} y_{i}\right)} \\
\frac{d y_{i}}{d f} & =-\frac{p^{\prime \prime} y_{i}}{p^{\prime}\left(2 p^{\prime}+p^{\prime \prime} y_{i}\right)} \quad(i=2, \ldots, n), \\
\frac{d n}{d f} & =\frac{4 p^{\prime}+2 p^{\prime \prime} y_{1}+(n-1) p^{\prime \prime} y_{i}}{p^{\prime} y_{i}\left(2 p^{\prime}+p^{\prime \prime} y_{i}\right)} .
\end{aligned}
$$

Because $y_{1}+(n-1) y_{2}=Y$, we have

$$
\frac{d Y}{d f}=\frac{d y_{1}}{d f}+(n-1) \frac{d y_{i}}{d f}+\frac{d n}{d f} y_{i}=\frac{2}{2 p^{\prime}+p^{\prime \prime} y_{i}}<0(i=2, \ldots, n) .
$$

Note that we have assumed that $p^{\prime \prime} y_{i}+p^{\prime}<0$ (condition for strategic substitute) and $p^{\prime}<0$.

In the first stage, firm 0 chooses $f$ so as to maximize $\pi_{0}+\pi_{1}$. The first-order condition of firm 0 is

$$
\frac{d\left(\pi_{0}+\pi_{1}\right)}{d f}=Y+\frac{2 f}{2 p^{\prime}+p^{\prime \prime} y_{i}}+\frac{y_{i}\left(2 p^{\prime}+p^{\prime \prime} y_{1}\right)}{2 p^{\prime}+p^{\prime \prime} y_{i}}-M^{\prime}(f)=0
$$

where $i \neq 1$. 


\subsection{Vertical separation}

Second, we consider the vertical separation case, that is, firm 0 maximizes $\pi_{0}$ with respect to $f$ and firm 1 maximizes $\pi_{1}$ with respect to $y_{1}$.

Consider the third stage. The first-order conditions of the downstream firms in the third stage are given by

$$
p(Y)+p^{\prime}(Y) y_{i}-f=0, \quad(i=1,2, \ldots, n) .
$$

In the second stage, due to the free entry condition, equation (4) holds.

These two conditions in (4) and (11) yield the equilibrium outcome given the regulated input price $f$. We investigate how a change in the input price affects the equilibrium outcome. The total differentials of these two conditions in (4) and (11) are given as

$$
\begin{array}{lll}
\left(n p^{\prime \prime} y_{i}+(n+1) p^{\prime}\right) d y_{i} & +y_{i}\left(p^{\prime \prime} y_{i}+p^{\prime}\right) d n & =d f \\
(n-1) p^{\prime} y_{i} d y_{i} & +y_{i}^{2} p^{\prime} d n & =y_{i} d f
\end{array}
$$

From the equations in (12), we have

$$
\begin{aligned}
\frac{d y_{i}}{d f} & =-\frac{p^{\prime \prime} y_{i}}{p^{\prime}\left(2 p^{\prime}+p^{\prime \prime} y_{i}\right)} \\
\frac{d n}{d f} & =\frac{2 p^{\prime}+n p^{\prime \prime} y_{i}}{p^{\prime} y_{i}\left(2 p^{\prime}+p^{\prime \prime} y_{i}\right)}
\end{aligned}
$$

From these results, we have

$$
\frac{d Y}{d f}=n \frac{d y_{i}}{d f}+\frac{d n}{d f} y_{i}=\frac{2}{2 p^{\prime}+p^{\prime \prime} y_{i}}<0
$$

Firm 0 maximizes $\pi_{0}$ with respect to $f$. The first-order condition is

$$
\frac{d \pi_{0}}{d f}=Y+f \frac{d Y}{d f}-M^{\prime}(f)=Y+\frac{2 f}{2 p^{\prime}+p^{\prime \prime} y_{i}}-M^{\prime}(f)=0
$$

\subsection{Comparison}

We now investigate how vertical separation affects the equilibrium outcomes under Cournot competition. Let the superscripts " $I C$ " and " $S C$ " denote the equilibrium outcomes under 
vertical integration and under vertical separation, respectively $(I, S$, and $C$ indicate Integration, Separation, and Cournot competition, respectively).

Lemma 1 Consider the equilibrium outcomes in the second stage given $f$. Then, for all $f$, (i) $y_{i}^{I C}(f)=y_{i}^{S C}(f)(i=2,3, \ldots, n)$, (ii) $Y^{I C}(f)=Y^{S C}(f)$ and $p^{I C}(f)=p^{S C}(f)$, and (iii) $Y^{S C}(f)$ is decreasing in $f$.

Proof See the Appendix.

Lemma 1 states that the type of vertical structure does not affect the total output and thus does not affect the consumer surplus at the free entry market. Because the type of vertical structure does not affect the total output under a given input price $f$, it does not affect firm 0 's profit. However, the type of vertical structure affects the profit of firm 1 . Thus, it affects the equilibrium level of $f$.

Proposition 1 Without the leadership by firm 1, vertical separation reduces the input price and increases consumer surplus.

Proof See the Appendix.

Proposition 1 states that vertical separation reduces the incentive of firm 0 for manipulation and thus reduces the resulting input price. An increase in the input price improves the competitive advantage of firm 1 and increases the joint profits of firms 0 and 1 . Such a strategic incentive disappears when the two firms are separated. This is why vertical separation reduces the input price. From Lemma 1(iii), this reduction in the input price increases the total output, which benefits consumers.

In the next section, we show that this result does not hold if the incumbent firm, firm 1 , can take Stackelberg leadership in the production market.

\section{Equilibrium outcomes with leadership by the incumbent}

In this section, we consider the situation in which the incumbent firm, firm 1, is the Stackelberg leader. We follow the standard model formulation of leadership in free entry markets discussed 
in Etro $(2006,2007)$. In the first stage, the input price $f$ is determined. In the second stage, firm 1 sets its quantity $y_{1}$. In the third stage, given $f$ and $y_{1}$, new entrants determine whether to enter the market. Finally, those entrants simultaneously choose their outputs.

Consider the third and the fourth stages. The first-order conditions of entrants and the free entry condition are the same as in the previous section. Given $f$ and $y_{1}$, these two conditions yield the equilibrium number of new entrants and the output of each new entrant. We discuss how $y_{1}$ affects these two variables. Let the superscripts " $I L$ " and " $S L$ " denote the equilibrium outcomes under vertical integration and under vertical separation, respectively $(I, S$, and $L$ indicate Integration, Separation, and the Leadership by the incumbent, respectively).

Lemma 2 Consider the subgame given $f$ and $y_{1}$. Regardless of $f$ and $y_{1}$, as long as $n>0$, (i) $y_{i}^{I C}(f)=y_{i}^{S C}(f)=y_{i}^{I L}(f)=y_{i}^{S L}(f)(i=2,3, \ldots, n)$, (ii) $Y^{I C}(f)=Y^{S C}(f)=Y^{I L}(f)=$ $Y^{S L}(f)$ and $p^{I C}(f)=p^{S C}(f)=p^{I L}(f)=p^{S L}(f)$, and (iii) $d n / d y_{1}=-1 / y_{2}$.

Proof See the Appendix.

Lemma 2(ii) implies that as long as $n>0$, the total output and the price do not depend on $y_{1}$. Thus, firm 1 serves as a price taker as long as $n>0$. Because the price must be higher than $f$ when $n>0$, firm 1 chooses $y_{1}$ to deter the entry of new entrants, resulting in $n=0$ under both vertical integration and vertical separation. Firm 1 chooses $y_{1}$ such that $p\left(y_{1}\right)=f+\left(K / y_{2}^{*}\right)$, where $y_{2}^{*}=y_{2}^{I C}=y_{2}^{S C}$. That is, $y_{1}$ is equal to $Y^{I C}(f)=Y^{S C}(f)$. This result has already been shown by Etro (2006) for the situation in which $f=0$. Under these conditions, we obtain the following lemma.

Lemma 3 Suppose that firm 1 is the Stackelberg leader. Then, no entry occurs under both vertical separation and vertical integration.

We now discuss how vertical separation affects the equilibrium input price. Under vertical 
integration, firm 0 chooses $f$ to maximize

$$
\begin{aligned}
\pi_{0}+\pi_{1} & =f y_{1}(f)-M(f)+\left(p\left(y_{1}(f)\right)-f\right) y_{1}(f) \\
& =p\left(Y^{I C}(f)\right) Y^{I C}(f)-M(f),
\end{aligned}
$$

note that $y_{1}(f)=Y^{I C}(f)$. Under vertical separation, it chooses $f$ to maximize

$$
\pi_{0}=f Y^{I C}(f)-M(f) .
$$

From the equations, we have the following proposition.

Proposition 2 Under the leadership by firm 1, vertical separation increases the input price and reduces the consumer surplus.

Proof See the Appendix.

This result contrasts with the result in the Cournot case (Proposition 1). Without the leadership by the incumbent in the production market, vertical separation reduces the incentive for manipulation, which reduces the input price. On the contrary, with the leadership by the incumbent, vertical separation stimulates the incentive of firm 0 for manipulation and thus increases the resulting input price. As discussed in Etro (2006), the incumbent produces aggressively, regardless of the input price. In contrast to the Cournot case, the strategic effect of raising the input price disappears under vertical integration. On the other hand, an increase in the input price reduces the output and the profit of firm 1, although firm 0 does not take this reduction into account under vertical separation. Thus, firm 0 has a stronger incentive to raise the input price. This is why vertical separation stimulates the manipulation under Stackelberg competition.

The two propositions indicate that the market structure is a critical determinant of how vertical separation affects the input price. If the incumbent occupies the leadership position and adopts its strategic behavior before new entry, vertical separation is harmful for consumers. 
Some readers may suspect that the difference between Propositions 1 and 2 comes from the difference between the properties of the solutions, not from whether the incumbent is the Stackelberg leader. No entry occurs in the Stackelberg case (complete entry deterrence, corner solution), although entry does occur (interior solution) in the Cournot case. This difference may be crucial. If we replace the assumption of constant marginal costs with that of increasing marginal costs, entry occurs even in the Stackelberg case. In the next section, we will check the robustness of our results by considering increasing marginal costs.

\section{Robustness check: Increasing marginal costs case with lead- ership}

In the previous section, in the Stackelberg case, we have shown that the corner solution (no entry) appears in equilibrium if the marginal costs of the firms are constant. In this section, we consider increasing marginal costs and investigate the situation in which entry occurs even under the leadership by the incumbent. Let $c\left(y_{i}\right)$ be the common production cost function of firm $i(i=1,2, \ldots, n)$. We assume that $c^{\prime}>0, c^{\prime \prime}>0$, and $c^{\prime \prime}$ is large in order to ensure an interior solution.

Consider the third and the fourth stages. The first-order condition and the zero-profit condition for each new entrant are, respectively,

$$
\begin{aligned}
(p(Y)-f)+p^{\prime}(Y) y_{i}-c^{\prime}\left(y_{i}\right) & =0 \\
(p(Y)-f) y_{i}-c\left(y_{i}\right) & =K .
\end{aligned}
$$

From almost the same calculations as in previous sections, we can show that Lemma 2 also holds under increasing marginal costs. We again obtain that the total quantity supplied by firms, $Y$, does not depend on $y_{1}$. Let $\tilde{Y}(f)$ denote the total quantity in this game. Firm 1 serves as the price taker as long as $n>0$. Contrary to the previous case, complete entry deterrence $(n=0)$ is not optimal for firm 1 because the marginal cost is increasing in quantity.

Firm 1 chooses $y_{1}$ such that $p(\tilde{Y}(f))$ is equal to its marginal cost. That is, under both vertical 
integration and vertical separation, firm 1 chooses $y_{1}$ such that $p(\tilde{Y}(f))=c^{\prime}\left(y_{1}\right)+f$. The type of vertical structure again does not affect the optimal output of firm 1. Some readers may think that firm 1's marginal cost is not $c^{\prime}\left(y_{1}\right)+f$ but $c^{\prime}\left(y_{1}\right)$ under vertical integration because it maximizes the joint profits of firms 0 and 1 and because $f y_{1}$ is just a transfer within the integrated firm. However, an increase in $y_{1}$ reduces the total output of new entrants by the same amount, thus reducing the revenue of firm 0 from the rivals. This means that $f$ is the marginal opportunity cost generated by increasing $y_{1}$ under vertical integration (Sappington $(2005))$.

In the first stage, firm 0 chooses $f$. Under vertical integration, firm 0 maximizes

$$
\pi_{0}+\pi_{1}=f \tilde{Y}(f)-M(f)+(p(\tilde{Y}(f))-f) y_{1}(f)-c\left(y_{1}(f)\right) .
$$

Under vertical separation, it maximizes

$$
\pi_{0}=f \tilde{Y}(f)-M(f)
$$

Comparing the two first-order conditions yields the following proposition.

Proposition 3 Suppose that the marginal cost of each firm is increasing in quantity. Consider an interior solution $(n>0)$. Under the leadership by firm 1, vertical separation increases the input price if $p^{\prime \prime}<0$. It does not change the input price if $p^{\prime \prime}=0$. It reduces the input price if $p^{\prime \prime}>0$.

Proof See the Appendix.

In the increasing marginal cost case, vertical separation can increase the input price and then reduce the consumer surplus. Vertical separation increases the input price if the demand is strictly concave. However, the result is weaker than that in the constant marginal cost case because this result does not hold if the demand is linear or strictly convex. If the inverse demand is strictly concave, one unit increase in $f$ increases the price at the product market by less than one unit. Thus, an increase in $f$ decreases the firm 1's profit $(p-f) y_{1}-c\left(y_{1}\right)$. Firm 0 does not care about this effect on firm 1's profit under vertical separation, implying that 
vertical separation raises $f$ if the inverse demand is strictly concave. However, if the inverse demand is strictly convex, one unit increase in $f$ increases the price at the product market by more than one unit. Thus, an increase in $f$ increases the firm 1's profit $(p-f) y_{1}-c\left(y_{1}\right)$. Firm 0 does not care about this effect on firm 1's profit under vertical separation, implying that vertical separation reduces $f$ if the inverse demand is strictly convex, in contrast to the concave demand function case.

\section{Concluding Remarks}

We have considered the situation wherein one firm holds an upstream bottleneck facility and new entrants use it at the regulated price (access fee) to provide final products. The bottleneck facility holder affects the regulated input price through the manipulation of access charge accounting. We have investigated how vertical separation affects the regulated input price in a free entry market. We discuss two cases: with and without the leadership by the incumbent firm in the product market. We find that vertical separation lowers the regulated input price without the leadership by the incumbent firm and that it raises the regulated input price with the leadership by the incumbent firm. Thus, to stimulate new entry by vertical separation, eliminating the leadership position by the incumbent is important.

We have assumed that the bottleneck facility holder can affect the regulated input price by manipulating the costs of the incumbent firm. We do not explicitly formulate a formal model analyzing the manipulating process. This important topic remains for future research.

\section{Appendix}

Proof of Lemma 1 If $f=0$, there is no difference between the two cases. Thus, $y_{i}^{I C}(0)=$ $y_{i}^{S C}(0)$ and $Y^{I C}(0)=Y^{S C}(0)$. Because (7) and (9) are, respectively, equal to (13) and (15), $y_{i}^{I C}(f)=y_{i}^{S C}(f)(i=2,3, \ldots, n)$ and $Y^{I C}(f)=Y^{S C}(f)$ for all $f$. This implies Lemmas $1(\mathrm{i})$ and (ii). (9) implies Lemma 1(iii).

Q.E.D. 
Proof of Proposition 1 Comparing (10) and (16), we have that (10) is larger than (16) given $f$ because $2 p^{\prime}+p^{\prime \prime} y_{i}<0$ for $i=1,2, \ldots, n$. Therefore, (10) yields a higher $f$ than (16). This implies Proposition 1.

Q.E.D.

Proof of Lemma 2 The first-order condition and the zero-profit condition for each new entrant are common under both vertical integration and vertical separation. Thus, the equation $y_{i}^{I L}(f)=y_{i}^{S L}(f)$ must hold. The total differentials of these two conditions (the first-order condition and the zero-profit condition for each new entrant) are given as

$$
\begin{array}{lll}
\left((n-1) p^{\prime \prime} y_{i}+n p^{\prime}\right) d y_{i} & +y_{i}\left(p^{\prime \prime} y_{i}+p^{\prime}\right) d n & =-\left(p^{\prime \prime} y_{i}+p^{\prime}\right) d y_{1} \\
(n-2) p^{\prime} y_{i} d y_{i} & +y_{i}^{2} p^{\prime} d n & =-p^{\prime} y_{i} d y_{1} .
\end{array}
$$

From these equations, we have $d y_{i} / d y_{1}=0(i=2,3, \ldots, n)$. Thus, the equation $y_{i}^{I L}(f)=$ $y_{i}^{S L}(f)$ does not depend on $y_{1}$. For any $y_{1}=y_{1}^{I C}(f)$, the equation $y_{i}^{I C}(f)=y_{i}^{I L}(f)$ must hold because the two conditions (the first-order condition and the zero-profit condition for each new entrant) in the Stackelberg case are exactly the same as those in the Cournot case. From this equation $\left(y_{i}^{I C}(f)=y_{i}^{I L}(f)\right)$ and Lemma $1\left(y_{i}^{I C}(f)=y_{i}^{S C}(f)\right)$, the equation $y_{i}^{I L}(f)=y_{i}^{S C}(f)$ holds. These imply Lemma 2(i).

From the zero-profit condition, we have $p^{j}(f)=f+K / y_{i}^{j}$ for $j=I C, S C, I L, S L$. Lemma 2(i) implies Lemma 2(ii).

$y_{1}^{j}+(n-1) y_{2}^{j}$ is fixed at $Y^{j}(f)$ for $j=I C, S C, I L, S L$. This implies that $d y_{1}+d n y_{2}=0$. From the equation, we have Lemma 2(iii).

Q.E.D.

Proof of Proposition 2 For expositional simplicity, we denote $Y^{I C}(f)$ by $Y(f)$. Under vertical integration, the first-order condition for firm 0 is

$$
\frac{d\left(\pi_{0}+\pi_{1}\right)}{d f}=Y^{\prime}(f)\left(p^{\prime} Y(f)+p\right)-M^{\prime}(f)=0 .
$$

Under vertical separation, the first-order condition for firm 0 is

$$
\frac{d \pi_{0}}{d f}=Y(f)+f Y^{\prime}(f)-M^{\prime}(f)=0 .
$$


The difference between $d\left(\pi_{0}+\pi_{1}\right) / d f$ in $(20)$ and $d \pi_{0} / d f$ in $(21)$ is

$$
\begin{aligned}
\frac{d\left(\pi_{0}+\pi_{1}\right)}{d f}-\frac{d \pi_{0}}{d f} & =-Y(f)+Y^{\prime}(f)\left(p^{\prime} Y(f)+p-f\right) \\
& =-Y(f)+p^{\prime} Y^{\prime}(f)\left(Y(f)-y_{i}(f)\right) \\
& =-Y(f)+\frac{2 p^{\prime}\left(Y(f)-y_{i}(f)\right)}{2 p^{\prime}+p^{\prime \prime} y_{i}(f)} \\
& =-\frac{y_{i}(f)\left(2 p^{\prime}+p^{\prime \prime} Y(f)\right)}{2 p^{\prime}+p^{\prime \prime} y_{i}(f)}<0
\end{aligned}
$$

where we use the first-order condition for each new entrant, $p-f=-p^{\prime} y_{i}$, to derive the second line and equation $(9), Y^{\prime}(f)=2 /\left(2 p^{\prime}+p^{\prime \prime} y_{i}(f)\right)$, to derive the third line. Because $p^{\prime}+p^{\prime \prime} y<0$ for all $y$ and $p^{\prime}<0$, the last line is negative. Therefore, given $f, d\left(\pi_{0}+\pi_{1}\right) / d f$ in (20) is smaller than $d \pi_{0} / d f$ in (21), implying that (20) yields a smaller input price, $f$, than

Q.E.D.

Proof of Proposition 3 Because the type of vertical structure does not affect $\pi_{0}(f)$, vertical separation increases (decreases, does not affect) the input price if and only if $\partial \pi_{1} / \partial f>$ $(<,=) 0$.

The total differentials of the three conditions (the first-order condition for firm 1, the first-order condition for each new entrant, and the zero-profit condition for each new entrant (firm $i)$ ) are given as

$$
\begin{array}{llll}
\left(p^{\prime}-c^{\prime \prime}\left(y_{1}\right)\right) d y_{1} & +(n-1) p^{\prime} d y_{i} & +y_{i} p^{\prime} d n & =d f \\
\left(p^{\prime \prime} y_{i}+p^{\prime}\right) d y_{1} & +\left((n-1) p^{\prime \prime} y_{i}+n p^{\prime}-c^{\prime \prime}\left(y_{i}\right)\right) d y_{i} & +y_{i}\left(p^{\prime \prime} y_{i}+p^{\prime}\right) d n & =d f \\
p^{\prime} y_{i} d y_{1} & +(n-2) p^{\prime} y_{i} d y_{i} & +y_{i}^{2} p^{\prime} d n & =y_{i} d f .
\end{array}
$$

From the equations, we have $\tilde{Y}^{\prime}(f)$ :

$$
\tilde{Y}^{\prime}(f)=\frac{d y_{1}}{d f}+(n-1) \frac{d y_{i}}{d f}+\frac{n}{d f} y_{i}=\frac{2 p^{\prime}-c^{\prime \prime}\left(y_{i}\right)}{p^{\prime}\left(2 p^{\prime}+p^{\prime \prime} y_{i}-c^{\prime \prime}\left(y_{i}\right)\right)} .
$$

The difference between the differential of $\pi_{0}+\pi_{1}$ with respect to $f$ under vertical integration and that of $\pi_{0}$ with respect to $f$ under vertical separation is

$$
\left(p^{\prime}(\tilde{Y}(f)) \tilde{Y}^{\prime}(f)-1\right) y_{1} .
$$


Using the result of $\tilde{Y}^{\prime}(f)$, we have

$$
\left(p^{\prime}(\tilde{Y}(f)) \tilde{Y}^{\prime}(f)-1\right) y_{1}=\frac{-p^{\prime \prime} y_{1}}{2 p^{\prime}+p^{\prime \prime} y_{i}-c^{\prime \prime}\left(y_{i}\right)} .
$$

Because the denominator is negative (the second-order condition of firm $i$ ), the fraction is negative (positive, zero) if and only if $p^{\prime \prime}<(>, 0)$. This implies Proposition 3. Q.E.D.

\section{References}

Armstrong, M. and Vickers, J. "The Access Pricing Problem with Deregulation: A Note." Journal of Industrial Economics, Vol. 46 (1998), pp. 115-121.

Baron, D. P. "Theories of Strategic Nonmarket Participation: Majority Rule and Executive Institutions." Journal of Economics and Management Strategy, Vol. 10 (2001), pp. $47-89$.

Brandão, A. and Castro, S. "State-Owned Enterprises as Indirect Instruments of Entry Regulation." Journal of Economics, Vol. 92(3) (2007), pp. 263-274.

Beard, T. R., Kaserman, D. L. and Mayo, J. W. "Regulation, Vertical Integration and Sabotage." Journal of Industrial Economics, Vol. 49 (2001), pp. 319-333.

Bustos, A. E. and Galetovic, A. "Vertical Integration and Sabotage with a Regulated Bottleneck Monopoly." B.E. Journal of Economic Analysis 83 Policy, Vol. 9 (2009), (Topics), Article 35.

Davidson, C. and Mukherjee, A. "Horizontal Mergers with Free Entry." International Journal of Industrial Organization, Vol. 25 (2007), pp. 157-172.

de Figueiredo, Jr., R.J.P. and Edwards, G. "Does Private Money Buy Public Policy? Campaign Contributions and Regulatory Outcomes in Telecommunications." Journal of Economics and Management Strategy, Vol. 16 (2007), pp. 547-576.

Economides, N. "The Incentive for Non-Price Discrimination by an Input Monopolist." International Journal of Industrial Organization, Vol. 16 (1998), pp. 271-284.

and White, L. J. "Access and Interconnection Pricing: How Efficient is the 'Efficient Component Pricing Rule'?" Antitrust Bulletin, Vol. 40 (1995), pp. 557-579.

Etro, F. "Aggressive Leaders." Rand Journal of Economics, Vol. 37(1) (2006), pp. 146-154. Competition, Innovation, and Antitrust: A Theory of Market Leaders and Its Policy Implications. Springer: New York, 2007.

"Stackelberg Competition with Endogenous Entry." Economic Journal, Vol.118 (2008), pp. 1670-1697. 
"Endogenous Market Structures and Strategic Trade Policy." International Economic Review, Vol. 52(1) (2011), pp. 63-84.

Gautier, A. and Mitra, M. "Regulation of an Open Access Essential Facility." Economica, Vol. 75 (2008), pp. 662-682.

Hausman, J. A. "Valuing the Effect of Regulation on New Services in Telecommunications." Brooking Papers on Economic Activity, Microeconomics, 1-38. 1997.

Higgins, R. S. and Mukherjee, A. "Deregulation Redux: Does Mandating Access to Bottleneck Facilities Necessarily Improve Welfare?" Public Choice, Vol. 142 (2010), pp. $363-377$.

Hori, K. and Mizuno, K. "Access Pricing and Investment with Stochastically Growing Demand." International Journal of Industrial Organization, Vol. 24(4) (2006), pp. 795808 .

Ida, T. Network Economics (Nihonhyoronsha, Tokyo, in Japanese) 2001.

and Anbashi, M. "Analysis of Vertical Separation of Regulators under Adverse Selection," Journal of Economics, Vol. 93 (2008), pp. 1-29.

Ino, H. and Matsumura, T. "What Role Should Public Enterprises Play in Free-Entry Markets?" Journal of Economics, Vol. 101 (2010), pp. 213-230.

and _How Many Firms Should Be Leaders? Beneficial Concentration Revisited." International Economic Review (to be published).

Laffont, J. J. and Tirole, J. "Access Pricing and Competition." European Economic Review, Vol. 38 (1994), pp. 1673-1710.

Mandy, D. M. and Sappington, D. E. M. "Incentives for Sabotage in Vertically Related Industries." Journal of Regulatory Economics, Vol. 31 (2007), pp. 235-260.

Marjit, S. and Mukherjee, A. "International Outsourcing and R\&D: Long-Run Implications for Consumers," Review of International Economics, Vol. 16 (2008), pp. 1010-1022.

Mukherjee, A. and Mukherjee, S. "Excess-Entry Theorem: The Implications of Licensing." Manchester School, Vol. 76(6) (2008), pp. 675-689.

Mizuno, K. and Shinkai, T. "Delegating Infrastructure Projects with Open Access." Journal of Economics, Vol. 88 (2006), pp. 243-261.

Rey, P. and Tirole, J. "A Primer on Foreclosure." Armstrong, M. and R. Porter (eds.), Handbook of Industrial Organization, Vol. 3, pp. 2145-2220, North-Holland, 2007.

Sappington, D. E. M. "On the Irrelevance of Input Prices for Make-or-Buy Decisions." American Economic Review, Vol. 95 (2005), pp. 1631-1638.

"On the Design of Input Prices: Can TELRIC Prices Ever be Optimal?" Information Economics and Policy, Vol. 18 (2006), pp. 197-215. 
Sarmento, P. and Brandão, A. "Access Pricing: A Comparison between Full Deregulation and Two Alternative Instruments of Access Price Regulation, Cost-Based and RetailMinus." Telecommunications Policy, Vol. 31 (2997), pp. 236-250.

Weisman, D. L. "Regulation and the Vertically Integrated Firm: The Case of RBOC Entry into Interlata Long Distance." Journal of Regulatory Economics, Vol. 8 (1995), pp. 249-266.

Viscusi, W. K., Harrington, J. E. and Vernon, J. M. Economics of Regulation and Antitrust. 4th Edition, MIT Press 2005.

Vogelsang, I. "Price Regulation of Access to Telecommunications Networks." Journal of Economic Literature, Vol. 41 (2003), pp. 830-862 